\title{
NORM industrial plants with potential radiological impact on workers and local population: First lessons from the review of available risk assessment studies in France
}

\author{
C. Cazala1 ${ }^{1}$, G. Loriot ${ }^{1}$, N. Pires ${ }^{1}$, T. Doursout ${ }^{1}$, F. Matouk ${ }^{2}$, A. Rannou ${ }^{1}$, \\ B. Cessac ${ }^{1}$ and A. Despres ${ }^{1}$ \\ ${ }^{1}$ Institute for Radiological Protection and Nuclear Safety (IRSN), \\ BP. 17, 92262 Fontenay-aux-Roses, France \\ ${ }^{2}$ Nuclear Safety Authority (ASN), 6 place du Colonel Bourgoin, \\ 75572 Paris Cedex 12, France
}

\begin{abstract}
The French Decree of 25 May 2005 [4] relative to activities using naturally occurring radioactive materials (NORM) not used because of their radioactive properties imposes that the operators assess effective doses received by workers and populations. To date, about sixty studies have been submitted to the French public authorities. Within this context, the French public authorities asked IRSN to develop a tool for evaluating the quality and the comprehensiveness of these studies and for identifying industrial plants with radiological protection problems. This tool is aimed at helping the regional representatives of French public authorities in their duty to analyse these studies. The aim of this presentation is to illustrate the application of the tool developed by IRSN and to present the French feedback.
\end{abstract}

\section{INTRODUCTION}

Some industrial activities such as ceramic production, coal combustion in power plants or mining and ore processing for the production of metals (tin, aluminium, ...) involve the use of materials, usually regarded as non-radioactive but which contain naturally occurring radionuclides (NORM). Working with these raw materials or storing them can lead to a significant increase in the exposure of workers and members of the public. According to the council Directive 96/29 Euratom [1], this matter must be considered from the radiological protection point of view. The French approach and the first feedback are presented hereafter.

\section{REGULATION}

The European Commission Directive concerning the handling of naturally radioactive materials was transposed in French regulations by two decrees ( $n^{\circ}$ 2002-460 of April 4, 2002 [2] and $n^{\circ} 2003-296$ of March 31, 2003 [3]) and by the Ministerial order of May 25, 2005 [4]. The latter sets a list of ten industries concerned by such a handling and imposes on the operators to assess the effective doses received by workers and populations. French authorities asked IRSN to evaluate the methods adopted by some operators for assessing these doses and to draw the first conclusions in terms of radiological protection. On the basis of this review, the list of the industries concerned may be reviewed either by addition or by deletion.

\section{AN INTERPRETATIVE FRAMEWORK}

To help the regional representatives of French public authorities in their analyse of the studies carried out by the operators in application of the French Ministerial order of May 25, 2005 [4], IRSN has set 
up an interpretative framework. This tool intends to evaluate the quality and the comprehensiveness of these studies and to highlight industrial activities where potential radiological protection concerns could be faced regarding occupational or public exposure.

This tool is designed in two steps as described in the figure 1:

- First step: it is an initial review of the study in order to determine either if it is complete, if effective doses calculated by the operator are significant or if the study is a generic assessment. At the end of this step, either the study will be sent back to the operator to be complemented, or a critical analysis of the study will be performed or the approach will be continued into the second step.

- Second step: a scoring matrix is applied in order to link exposure and hazards. The aim is to score:

o the quality of the dose assessments presented by operators (descriptions of the physical and chemical forms of materials, of the radiological characterizations, of the exposure pathways, ...),

$\circ$ the effective dose levels.

When the score is greater than a defined threshold, the study needs a careful examination and a critical analysis. Otherwise, the assessment is considered to show no significant radiological protection issue and to need no further examination within the general review process.

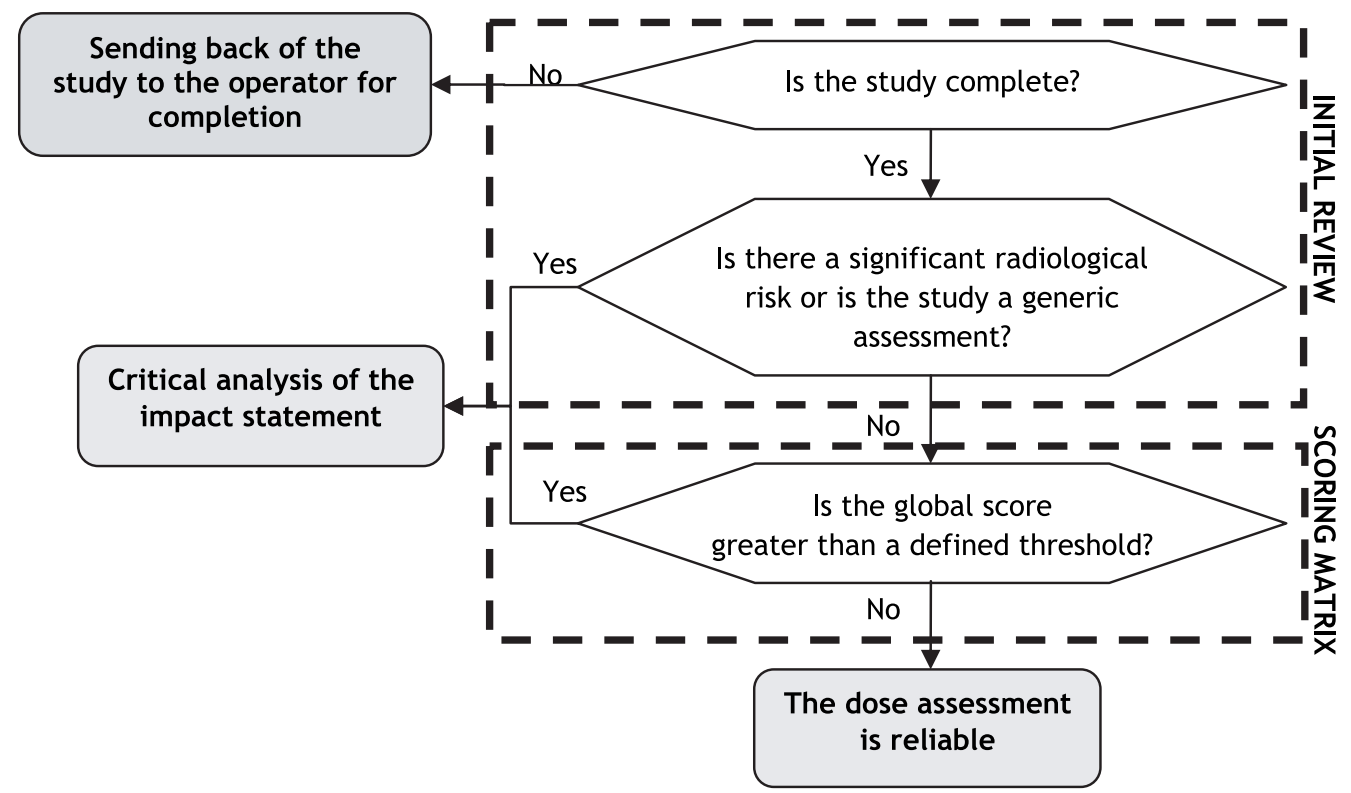

Figure 1. Logical diagram of the interpretative framework.

\section{FRENCH FEEDBACK}

Since the publication of the French Ministerial order of May 25, 2005 [4], IRSN has received sixtysix studies which deal with eight types of industrial facilities. The majority of the studies (sixty-three studies) deals with workers exposure and only twelve studies deal with populations exposure. Figure 2 shows the breakdown of studies by the different kinds of industrial facilities.

Figure 3 shows the distribution of the doses calculated by the operators. For workers, half of the doses calculated is less than $0,25 \mathrm{mSv}$ per year and $86 \%$ of the doses calculated is less than $1 \mathrm{mSv}$ per year, the limit for non exposed workers. For populations, half of the doses calculated is less than $10 \mu \mathrm{Sv}$ per year and all of these are less than $1 \mathrm{mSv}$ per year, the limit for populations exposure. 

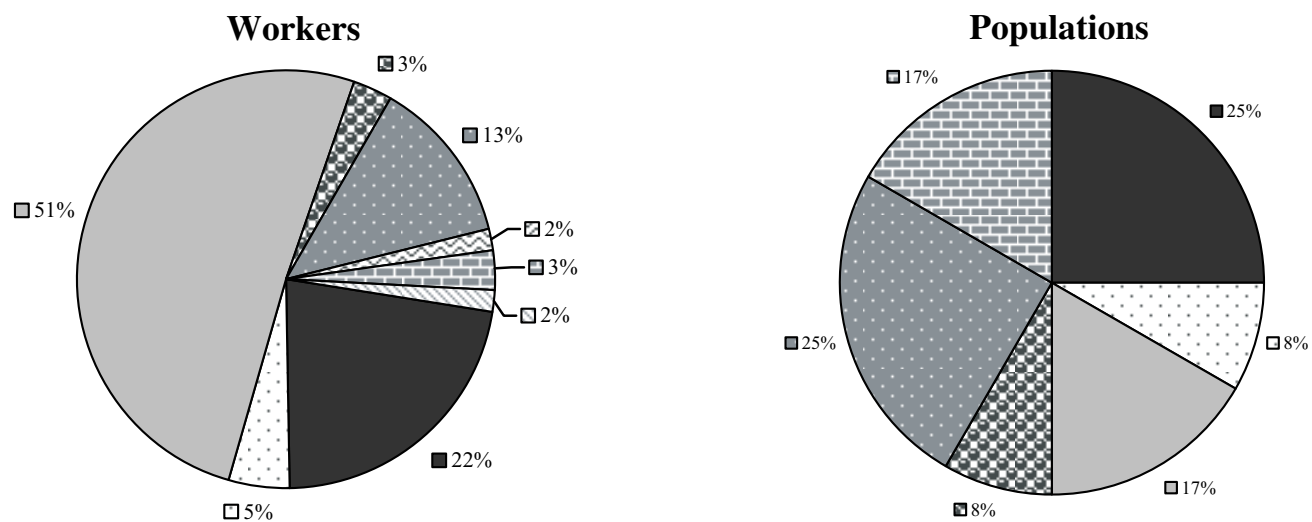

Coal combustion in power plants

$\square$ Treatment of tin, aluminium, copper, titanium, niobium, bismuth and thorium ores

$\square$ Production of refractory ceramics and smelting, metallurgy and glass industry using them

因 Production or use of compounds with thorium

$\square$ Production of zircon and baddeleyite, and smelting or metallurgy plants using it

$\unrhd$ Production of phosphated fertilizers and phosphoric acid

$\square$ Treatment of titanium dioxide

⿴囗十 Treatment of rare earths and production of pigments containing them

$\boxplus$ Underground water treatment by filtration

$\triangle$ Spas

Figure 2. Breakdown of studies by the different kinds of industry.

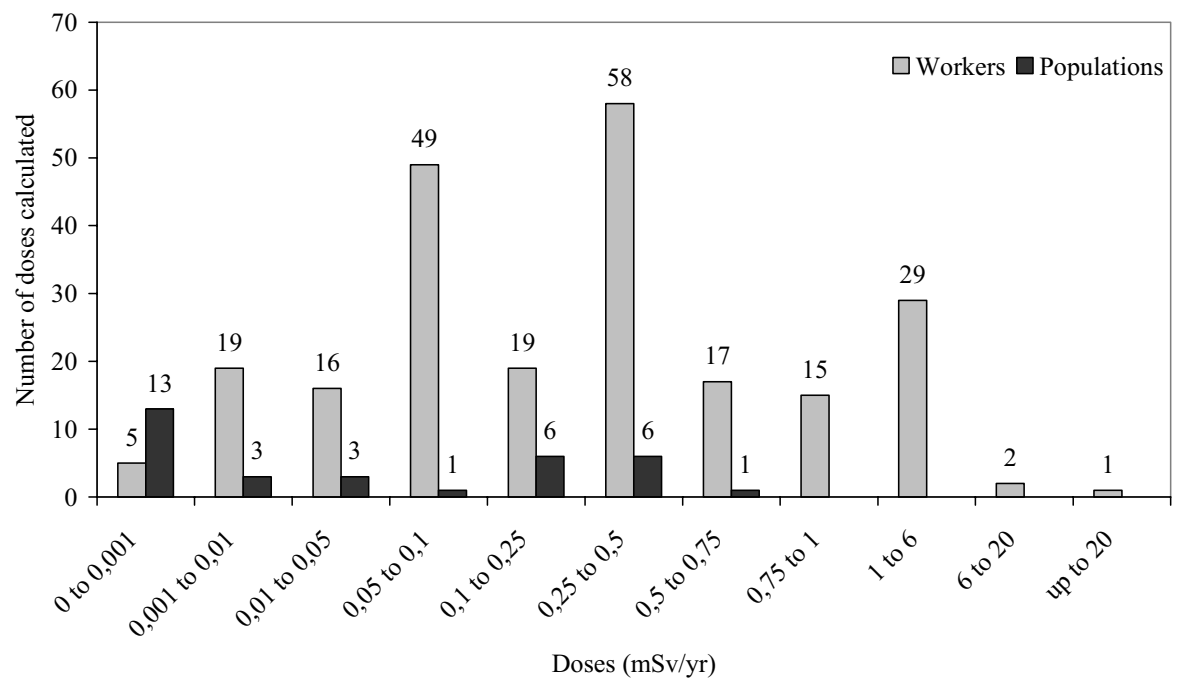

Figure 3. Distribution of the effective doses calculated by the operators for workers and populations. 


\section{CONCLUSION}

Based on the recent feedback gained by IRSN and French authorities on the studies conducted by operators, the following conclusions can be drawn:

- assessments are still expected for some industries concerned by the French Ministerial order of May 25, 2005 [4];

- the assessments on populations are often unconsidered;

- about $15 \%$ of calculated doses for workers are grater than the limit of $1 \mathrm{mSv}$ per year and need a further examination;

Nevertheless, even if the usefulness of the tool is demonstrated, users have to keep in mind that this interpretative framework is not devoted to replace a critical analysis of the studies but only to identify those which require a specific attention such as studies with a dose greater than $1 \mathrm{mSv}$ per year.

\section{References}

[1] Council Directive 96/29/Euratom of 13 may 1996 laying down basic safety standards for the protection of the health of workers and the general public against the dangers arising from ionizing radiation

[2] Decree $\mathrm{n}^{\circ}$ 2002-460 of April 4, 2002 relative to the radiation protection of the population

[3] Decree $\mathrm{n}^{\circ}$ 2003-296 of March 31, 2003 relative to the radiation protection of workers

[4] Ministerial order of May 25, 2005 about activities using NORM not used because of their radioactive properties 